\title{
Exploring the factors affecting purchase intention towards green packaged products of Indian consumers
}

\author{
Raj Karan Gupta \\ School of Business Studies, Sharda University, Greater Noida, U.P. India
}

\begin{abstract}
Today, sustainable packaging has become an important way towards achieving the sustainable development by protecting the environment. This paper is an attempt to investigate the factors which affect the intention of Indian consumers towards green packaging, a packaging which is not harmful to the environment. This study considers three factors/ variables namely environmental concern, attitude towards green packaging and willingness to pay as independent variables and purchase intention of consumers towards green packaged products as dependent variable. The data have been collected from 111 respondents and have been analysed by using SPSS software. The correlation and regression analysis were performed to reach the conclusion that which factor affects how much towards consumers' purchase intention of green packaged products. Findings of this study demonstrated that all the three variables (environmental concern, attitude towards green packaged products and willingness to pay) have a positive effect on the dependent variable (consumers' intention towards green packaged products).
\end{abstract}

\section{Introduction}

A sustainable environment has become the need of the hour and efforts are being made all over the world towards achieving the sustainable development. Also, because of the energy crisis and climate change situations, there is a growing concern about environmental issues [1]. In addition to that green consumption behaviour has also been considered as an environmentally responsible behaviour aiming to protect the ecology which has attracted the attention of both the enterprises and the consumers as well [2-4]. As we know that it is not only the green product which is important towards sustainable environment but also the green packaging is equally important for protecting our environment. Ecological packaging / green packaging is helpful in protecting the environment by reducing the packaging waste [5]. Further, the impact of packaging on the environment has gained more attention as it is considered as main contributor of waste [6]. A good packaging is not only intended to protect the main product but should also be eco-friendly in nature. But there are few implications of producing such green products / or products having eco-friendly packaging / green packaging as these green products / green packaged products carry extra cost and hence consumers need to pay more prices for such products and packaging. Thus, it becomes important that a manufacturer should know what really motivates / affects the consumers' choice / preference of green products or green packaged products. With this need, this paper is intended to provide an insight on the factors affecting the consumers' intention towards purchasing green packaged products. This study is not only going to benefit the business organizations towards developing their understanding and strategies of green packaging / sustainable packaging but also provide benefits to policy makers towards their policy making in this regard.

\section{Objectives, research questions and proposed framework}

\subsection{The research objectives}

The objectives of this study are to:

- Investigate the causal relationship among the independent variables (environmental concern, attitude towards green packaging and willingness to pay) and dependent variable (purchase intention towards green packaged products).

- Develop an understanding of the most influencing factor towards consumers' intention of green packaging.

\subsection{The research questions}

This study tries to address the following research questions:

- How much environmental concern contributes in shaping the consumers' intention towards green packaged products?

- To what extent, consumers' attitude affects the consumers' intention towards green packaged products?

- How much the willingness to pay really matters in shaping consumers' purchase intention of green packaged products? 


\subsection{The research framework}

This research study uses the following framework:

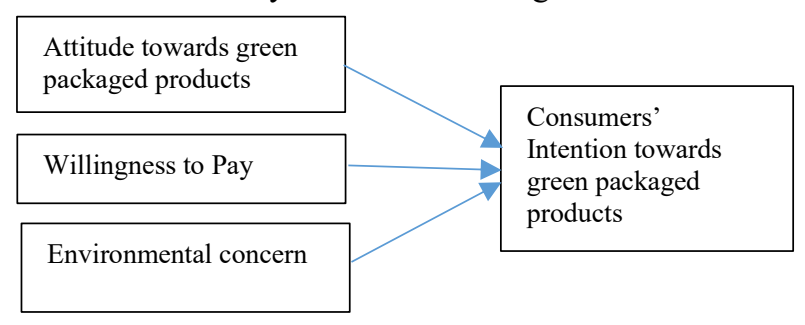

Fig. 1. Proposed research framework

\section{Literature review and hypotheses development}

Green consumption behaviour can be considered as a behaviour which is more eco-friendly in terms of use and disposal of eco-friendly products [7,8]. Understanding purchase intention is also important as there are studies $[7,9,10,11]$ which concluded that green consumption intention can be used to understand the green consumption behaviour as well.

\subsection{Attitude towards green packaged products}

Attitude is an important predictor of the behavioural intention and the actual behaviour as well. Consumer's attitude plays an important role in determining the purchase intention of green packaged products [12]. There are several studies which establishes a link between attitude towards green packaging and the purchase intention of green packaged products [12]. In another study [6] it was found that there is a close relationship between the consumers' attitude towards the liking and disliking which further determines the purchase intention of products having green packaging. In another study [13], it was concluded that consumers' attitude has a positive effect on their choice of green packaged products. Hence, the following hypothesis was formulated for this study.

H1: Consumers' attitude towards green packaged products positively affects their purchase intention of green packaged products.

\subsection{Willingness to pay and purchase intention towards green packaged products}

Willingness to pay also plays an important role in determining the purchase intention and behaviour towards green packaged products. Several studies found a close relationship between consumers' willingness to pay and their purchase intention of green products / green packaged products. Further, it is now a widely accepted fact that green products or products having green packaging are more expensive than non-ecofriendly products. A consumer who is willing to consume green products / green packaged products will also have to be ready to pay a higher price as compared to conventional products [14]. Further, green consumer behaviour of consumers also requires sacrifice of more money $[15-16,9]$. Studies $[10,17,18]$ concluded that price sensitivity is an important element and can be seen as a direct or indirect antecedent for the purchase intention of eco-friendly/green products.

$\mathrm{H}$ 2: The willingness to pay has a positive effect on the purchase intention towards green packaged products.

\subsection{Environmental concern and purchase intention towards green packaged products}

Environmental concern can be understood as the individual care for the ecology and environment and is an important antecedent towards the green consumption intention [19-21]. In a study [16], it was found that individuals having higher environmental responsibility and concern were supporting more green products / products having green packaging. Few more studies $[17,22,23]$ also demonstrated a direct positive effect of environmental concern on the green consumption. Further, individuals having higher level of environmental concern are more willing to take care of the environmental issues and taking appropriate actions towards environmental protection [17]. In a study [12], a confirmed relationship was established between the environmental concern and intention towards green packaged product. People having more information and awareness about the environment issues and concerns have been found to prefer more green packaging [5].

H3: Environmental concern positively affects the purchase intention of green packaged products.

\section{Methodology}

\subsection{Data collection and instrument}

This study is empirical in nature. Data have been collected by using a structured questionnaire. After going through the literature available in this regard, a structured questionnaire was developed. There were two sections of the questionnaire. Section-I contained the details asking the personal and demographic information of the respondents while section-II was intended to collect the data on the variables / factors used in this study. A total of 18 items / questions (five items to measure attitude towards green packaged products, three items to measure willingness to pay, six items for environmental concern and four items to measure the purchase intention towards green packaged products) were included in the questionnaire. Respondents were asked to rate their responses on a five-point Likert scale (1 for strongly disagree to 5 for strongly agree). The reliability test of the questionnaire was also performed and the reliability statistics of the instrument is presented in Table- 1 .

Table-1 clearly indicates that the used questionnaire / instrument was found reliable with the Cronbach's Alpha value (.905) for 18 items used in the instrument.

Table 1. Reliability Statistics 


\begin{tabular}{|r|rr|}
\hline \multicolumn{2}{|r|}{ Cronbach's Alpha } & \multicolumn{2}{|c|}{ N of Items } \\
\hline .905 & & 18 \\
\hline
\end{tabular}

\subsection{Correlation matrix}

The details of the corelation have been provided in Table-2.

Table 2. Correlation matrix Correlations

\begin{tabular}{|c|c|c|c|c|c|}
\hline & & $\begin{array}{c}\text { Pur_In } \\
\text { t_GP }\end{array}$ & $\begin{array}{c}\text { E_Con } \\
\text { cern }\end{array}$ & $\begin{array}{c}\text { GP_Att } \\
\text { itude }\end{array}$ & $\begin{array}{l}\text { Will_P } \\
\text { ay_M }\end{array}$ \\
\hline & Pearson & 1 & $.540^{* *}$ & $.610^{* *}$ & $.607^{* *}$ \\
\hline r Int & Correlation & & & & \\
\hline _GP & Sig. (2-tailed) & & .000 & .000 & .000 \\
\hline & $\mathrm{N}$ & 111 & 111 & 111 & 111 \\
\hline & Pearson & $.540^{* *}$ & 1 & $.430^{* *}$ & $.286^{* *}$ \\
\hline E_Conc & Correlation & & & & \\
\hline ern & Sig. (2-tailed) & .000 & & .000 & .002 \\
\hline & $\mathrm{N}$ & 111 & 111 & 111 & 111 \\
\hline & Pearson & $.610^{* *}$ & $.430^{* *}$ & 1 & $.431^{* *}$ \\
\hline GP_Att & Correlation & & & & \\
\hline itude & Sig. (2-tailed) & .000 & .000 & & .000 \\
\hline & $\mathrm{N}$ & 111 & 111 & 111 & 111 \\
\hline & Pearson & $.607^{* *}$ & $.286^{* *}$ & $.431^{* *}$ & 1 \\
\hline Will_Pa & Correlation & & & & \\
\hline y_M & Sig. (2-tailed) & .000 & .002 & .000 & \\
\hline & $\mathrm{N}$ & 111 & 111 & 111 & 111 \\
\hline
\end{tabular}

**. Correlation is significant at the 0.01 level (2-tailed).

A positive correlation has been found between all the independent variables with the dependent variable used in this study with the coefficient values (environmental concern +.540 , attitude towards green packaged products +.610 and + willingness to pay +.607$)$ consecutively.

\subsection{Model summary}

Model summary has been presented in Table-3.

Table 3. Model Summary

\begin{tabular}{|l|r|r|r|r|}
\hline $\begin{array}{l}\text { Mode } \\
\mathbf{1}\end{array}$ & \multicolumn{1}{|c|}{$\mathbf{R}$} & $\begin{array}{c}\text { R } \\
\text { Square }\end{array}$ & \multicolumn{1}{c|}{$\begin{array}{c}\text { Adjusted R } \\
\text { Square }\end{array}$} & $\begin{array}{r}\text { Std. Error of } \\
\text { the Estimate }\end{array}$ \\
\hline 1 & $.766^{\mathrm{a}}$ & .586 & .575 & .45865 \\
\hline
\end{tabular}

a. Predictors: (Constant), E_Concern, Will_Pay_M,

GP_Attitude
The R Square value (.586) in Table-3 indicates that the independent variables (environnemental concern, attitude towards green packaged products and willingness to pay) explain 58.6\% variation in the dependent variable (purchase intention towards green packaged products).

\subsection{Coefficient and hypotheses testing}

The coefficient values are presented in Table-4. The H1 hypothesis has been supported as the B value of attitude towards green packaged product was found (.355) with the $p$-value of $<.05$ which means that attitude towards green packaged product has a positive influence on the purchase intention of green packaged products.

Table 4. Coefficient matrix Coefficients ${ }^{\mathrm{a}}$

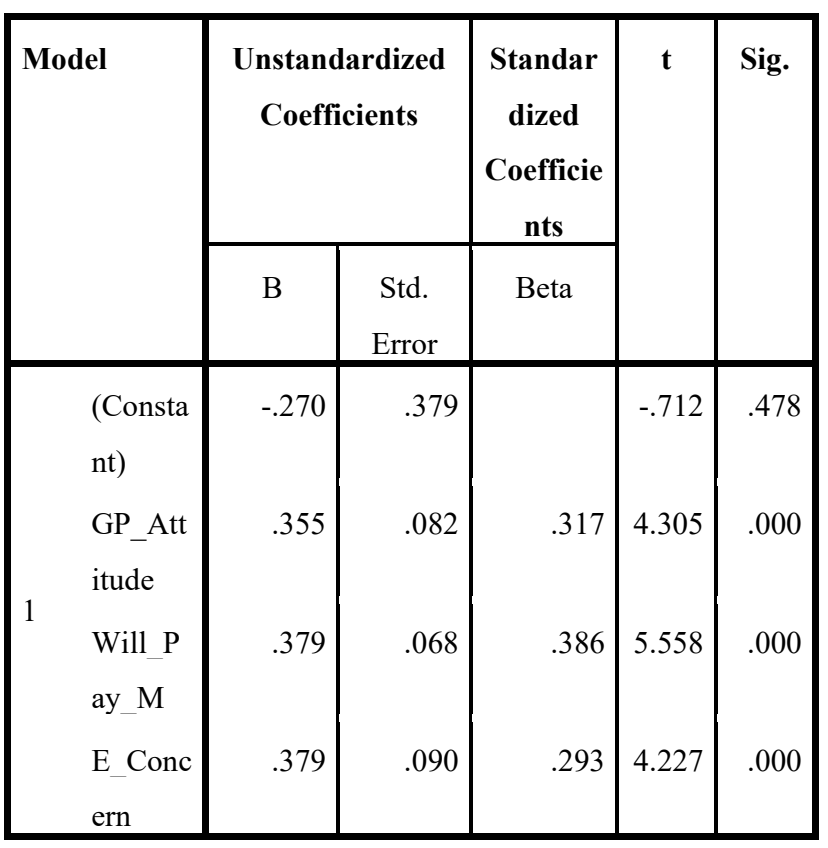

a. Dependent Variable: Pur_Int_GP

Similarly, the findings of this study also support $\mathrm{H} 2$ and H3 hypotheses with a value willingness to pay $(.379$; $\mathrm{p}$ value $<.05)$ and environmental concern $(.379 ; \mathrm{p}$-value $<.05)$ consecutively. Hence, it can be said that all the independent variables (environnemental concern, attitude towards green packaged product and willingness to pay) have a positive effect on the dependent variable (purchase intention towards green packaged products). Further, this study also revealed willingness to pay as the most influencing factor to determine the purchase intention of consumers towards green packaged products with a Beta value of (.386).

\section{Conclusion and suggestions}

From the findings of this study, it can be concluded that environmental concern, attitude towards green packaging and willingness to pay all have a positive effect on the purchase intention of consumers towards their choice of green packaged products. The findings very much indicate that if we improve the attitude of consumers towards green packaging, and convince them towards the premium price charged for green products / 
green packaging and also improve their environmental concern and knowledge, consumers would be ready to prefer more green packaged products. This will further create the opportunities for new firms also to supply sustainable packaging materials used in such type of green packaging. Further, to improve the attitude and environmental concern, appropriate training and campaign can be launched not only by the firms but also by the government/ agencies involved in environment protection / sustainable development. The promotion of such green products or products having green packaging would contribute a lot in protecting our environment and will also be helpful in achieving the sustainable development goals. Offering incentives and subsidies may also be an important way towards promoting such kind of green packaged products. The incentives and subsidies can be provided not only to firms engaged in manufacturing of green products / using green packaging materials but also to consumers for compensating their sacrifices in terms of higher prices for using green packaged products.

\section{Limitations and direction for future work}

Like other studies, this study also has its own limitations. One of the limitations is that this study is based on a small sample size of 111 respondents and focusing only a limited number of factors (three factors) to predict the purchase intention of consumers towards green packaged products. However, this study provides a basis to conduct similar kind of work by incorporating more variables and covering a large geographic area with a larger sample size to develop more understanding about green product purchase intention / or purchase intention towards products having green packaging.

\section{References}

1. K. Skogen, H. Helland, B. Kaltenborn, J. Nat. Conserv., 44, 12 (2018).

2. H.M. Gonçalves, T.F. Lourenço, G.M. Silva, J. Bus. Res., 69, 1484 (2016).

3. E. Semprebon, D. Mantovani, R. Demczuk, C. S. Maior, V Vilasanti,. Intell. Plan., 37, 18 (2019).

4. J. Urban, S. Bahnik, M.B. Kohlova, J. Environ. Psychol., 63, 139 (2019).

5. C. Parkash, K. R. Do Journal of Ret. and Cons. Serv., 163-169(2019).

6. Mishra, J. Have Green, Pay More: An Empirical Investigation of Consumer's Attitude towards Green Packaging in an Emerging Economy. In Essays on Sustainability and Management, 125150(2017).

7. G. Sheng, F. Xie, S. Gong, H. Pan, Int. J. Cons. Stud., 43, 315 (2019).

8. A.Pagiaslis, A.K. Krontalis, Psychol. Mark., 31, 335 (2014).
9. A. Al Mamun, M.R. Mohamad, M.R.B. Yaacob, M. Mohiuddin, J. Environ. Manag., 227, 73 (2018).

10. Z. Ghali-Zinoubi, M. Toukabri, Trends. Food. Sci. Technol., 90, 175 (2019).

11. H. Albloushy, K.Y. H. Connell, Int. J. Consum. Stud., 43, 390 (2019).

12. G. Prakash, P. Pathak, Journal of Cleaner Prod., 141, 385 (2017)

13. S. Mkik, A. Amina, J. of Bus. And Management, 13, 71 (2019).

14. J. Rana, J. Paul, Journal of Ret. and Consum. Serv., 38, 157 (2017).

15. B.W. Husted, M.V. Russo, C.E.B. Meza, S.G. Tilleman, J. Bus. Res., 67, 891 (2014).

16. B. Chekima, S.A.W. Wafa, O.A. S. Igau, Chekima, S.L. Sondoh, J. Clean. Prod., 112, 3436 (2016).

17. C. Stall-Meadows, A. Davey, J. Glob. Fash. Mark. 4, 33 (2013).

18. U.J.J. Hahnel, C. Ortmann, L. Korcaj, H. Spada, J. Environ. Psychol., 40, 306 (2014).

19. K. White, B. Simpson, J. Mark., 77, 78 (2013).

20. S. McDonald, C.J. Oates, M. Thyne, A.J. Timmis, C. Carlile, J. Mark. Manag., 31, 1503 (2015).

21. J.A. Roberts, D.R. Bacon, J. Bus. Res., 40, 79 (1997).

22. M.M. Mostafa, Expert Syst. Appl., 36, 11030 (2009).

23. N. M. Suki, J. Clean. Prod., 132, 204 (2016). 